\title{
Monitoring Earthquake Shaking in Buildings to Reduce Loss of Life and Property
}

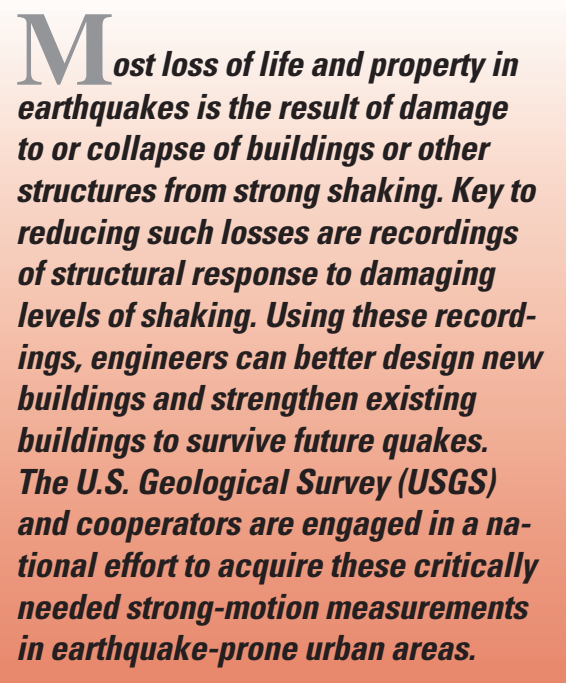

Strong earthquake shaking can damage vulnerable buildings, dams, and other structures, causing catastrophic loss of life and property in densely urbanized areas. For example, the 1994 Northridge, California, earthquake (magnitude 6.7) caused more than $\$ 20$ billion in structural damage and killed 57 people in the greater Los Angeles region. Reducing such losses requires measurements of structural response to strong levels of earthquake shaking in structures likely to be damaged.

Under the National Earthquake Hazards Reduction Program enacted by Congress in 1977, the U.S. Geological

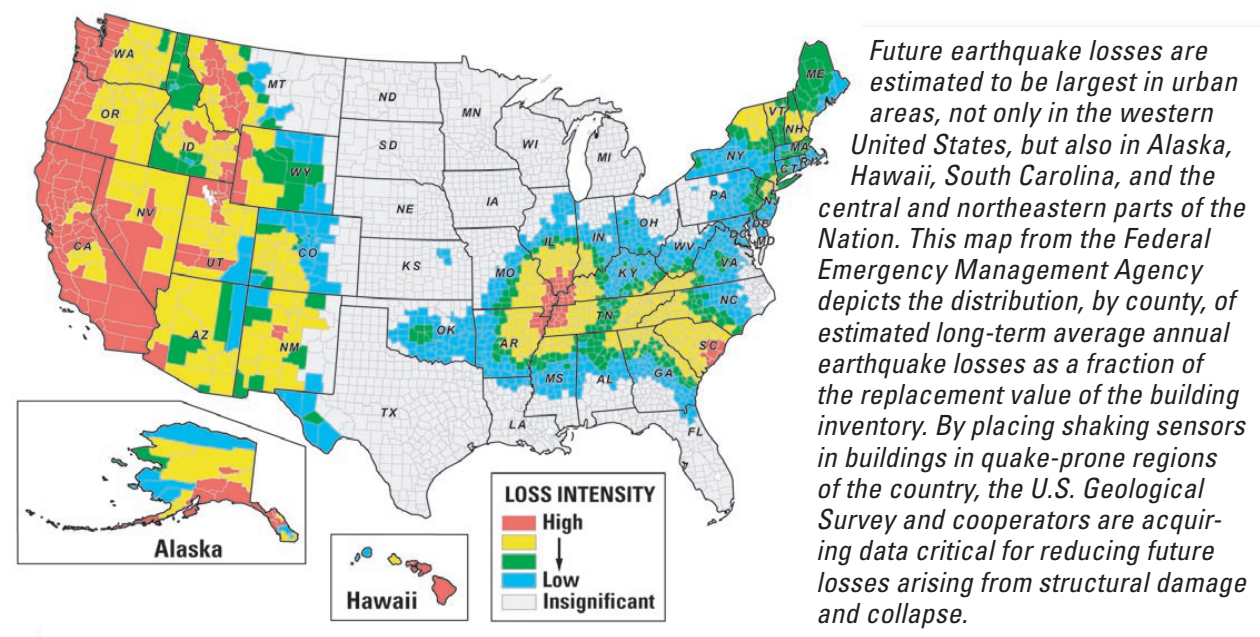

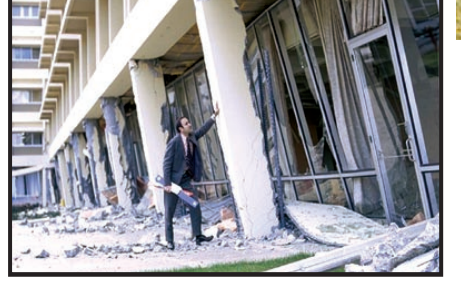

Survey (USGS) has responsibility for the Federal effort to acquire strong-motion measurements in structures throughout the United States. Engineers need these critical measurements so that they can better design new structures to survive future quakes. In pursuit of this goal, the USGS cooperates with other structural monitoring programs, such as those of the California Geological Survey, Army United States, but also in Alaska, Hawaii, South Carolina, and the central and northeastern parts of the depicts the distribution, by county, of estimated long-term average annual earthquake losses as a fraction of in buildings in quake-prone regions of the country, the U.S. Geological losses arising from structural damag collapse.

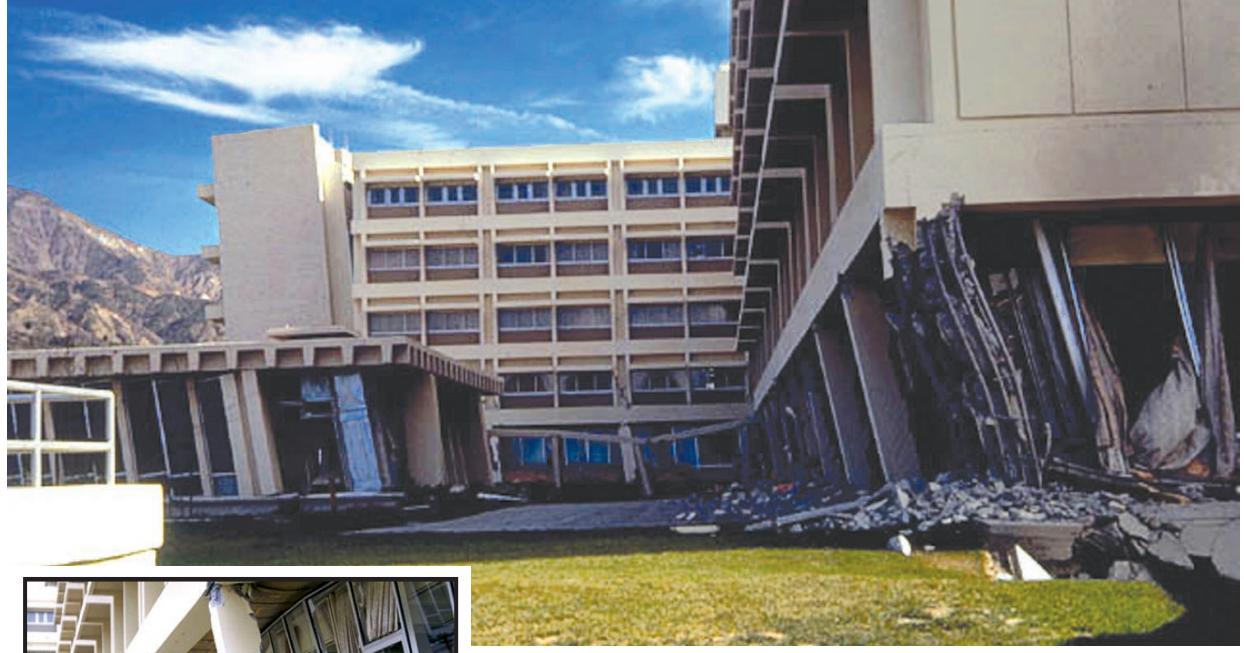

Corps of Engineers, General Services Administration, and University of Puerto Rico, Mayagüez.

\section{Earthquake Monitoring in Buildings}

Few buildings in urban areas threatened by damaging earthquakes are currently equipped with seismic sensors. However, recordings from such sensors are critical to designing safer buildings and preventing loss of life by:

- Understanding how damage from strong shaking occurs,

- Evaluating and improving earthquake-resistant design strategies and also methods for predicting the seismic performance of structures,

- Improving earthquake provisions of building codes, and

- Assessing building safety immediately following a damaging quake.

Although progress has been limited by the lack of shaking records from buildings damaged during strong earthquakes, records from buildings obtained to date have enabled progress on all of these fronts: 


\section{MONITORING THE ONSET OF STRUCTURAL DAMAGE}

Recordings of earthquake shaking within a

heavily damaged building are rare-even today.

The first set of such records was obtained in 1979

from southern California when a magnitude 6.4

earthquake seriously damaged this modern office

building in the Imperial Val-

ley. The estimated cost to

repair the reinforced-con-

crete frame and shear-wall

building was so large that

the building was razed.

The photo at far right

shows the evolving failure

of columns at one end of

the building.

The California Geological Survey (formerly

the California Division of

Mines and Geology) had installed

13 motion sensors at various points

throughout the structure to document

its swaying and twisting in an earth-

quake. Shown above the building is

the roof-level record of horizontal ac-

celeration parallel to the long axis of

the structure. The sudden lengthen-

ing of vibrations at $A$ (7 seconds after

shaking begins) marks the onset of structural damage. About 4 seconds later (at $B$ ), faint high-frequency vibrations (rapid small pulses), superimposed on the slower vibrations, signal the collapse of columns.

Such records from buildings that suffer earthquake damage enable engineers to document and investi-
Column collapse

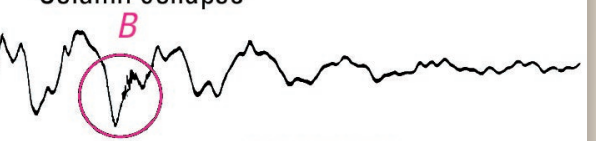

0

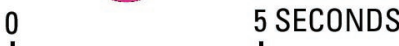
.

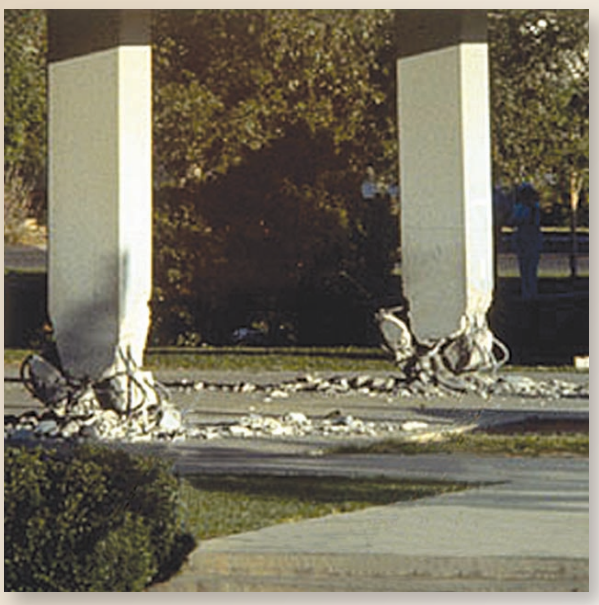

gate failure processes and to devise and improve methods for minimizing structural damage in future shocks.

\section{Understanding how damage occurs-}

Only a few records of shaking have been obtained in buildings seriously damaged by an earthquake. Such records are needed to document and understand how damage begins and progresses during intense seismic shaking. They are crucial to reducing or avoiding future quake losses. For example, during the 1994 Northridge earthquake, numerous steel-frame buildings were unexpectedly damaged, but only two damaged, steel-frame buildings in the region had been instrumented with shaking sensors. In the shaken urban area, about 300 steel-frame buildings that did not have shaking sensors were investigated for damage - a long and costly process. Having recorders in many of these buildings would have yielded invaluable information on (1) what types of buildings suffered damage to their steel frames,

(2) why such damage occurred, and (3) what might be solutions for repair and strengthening of the damaged structures.

Improving earthquake resistanceLarge losses from earthquakes striking major urban areas in quake-conscious California and Japan during the past two decades have prompted new approaches to building earthquake resistant structures. One new strategy for safeguarding a building is partially "decoupling" the building from the ground at its base, thereby reducing the earthquake forces acting on the structure. The potential payoff from such a protective strategy, known as base isolation, can be evaluated by recording earthquake motion in the structure above the isolators as well as in the ground beneath them and then comparing the shaking level in the building to that in a similar structure with a conventional foundation.

Upgrading building codes-Monitored structures provide essential data for confirming and (or) improving building-code provisions and design procedures. Response data from structures subjected to design-level shaking allow comparison of actual building behavior and performance to those anticipated and intended by design codes and procedures. Significant differences between what is expected and what actually is measured prompts new code provisions and design practices, or revisions to them, so that future building de- signs and remedial strengthening better withstand strong shaking. The upgrading of codes and practices is a deliberative, continuous process. Two examples of advances spurred by response data are (1) increasing the flexural restraint of large-span floors and roofs and (2) incorporating the dynamic interaction of a building foundation with the surrounding soil in calculation of the building performance in a strong design earthquake.

Assessing building safety - As design procedures and analysis tools improve, earthquake engineers and building owners are embracing performance-based design. Structures are being designed for specific quake-performance levels chosen by owners and engineers, such as allowable level of damage. This design strategy implies knowledge of the deformation of the overall structure during an earthquake, as well as of its component elements. Such knowledge requires measurement of the motion at several heights within the structure to determine its deformation. When the deformation exceeds a prescribed threshold value, the building manager can gauge the health Continued on back page 


\section{EVALUATING EARTHOUAKE PROTECTION}

One engineering strategy for reducing earthquake damage is to partially decouple, or isolate, a building from ground shaking in an earthquake. This strategy, called base isolation, is increasingly used to safeguard important structures. Building response recorded by the California Geological Survey in the 1994 Northridge earthquake (magnitude 6.7) confirmed the promise of the base-isolation strategy.

The 8-story steel superstructure of the University of Southern California (USC) University Hospital in Los Angeles is supported by 149 isolators (see photos) sitting on continuous concrete footings. During the Northridge earthquake, motions recorded at the top of the isolators and at the roof were less than those recorded in the ground below the isolators and at a nearby site removed from the building. The isolators reduced the level of motion fed into the base of the building by about two-thirds. The peak shaking at roof level was only about $40 \%$ of that recorded on the ground about 200 feet from the building,

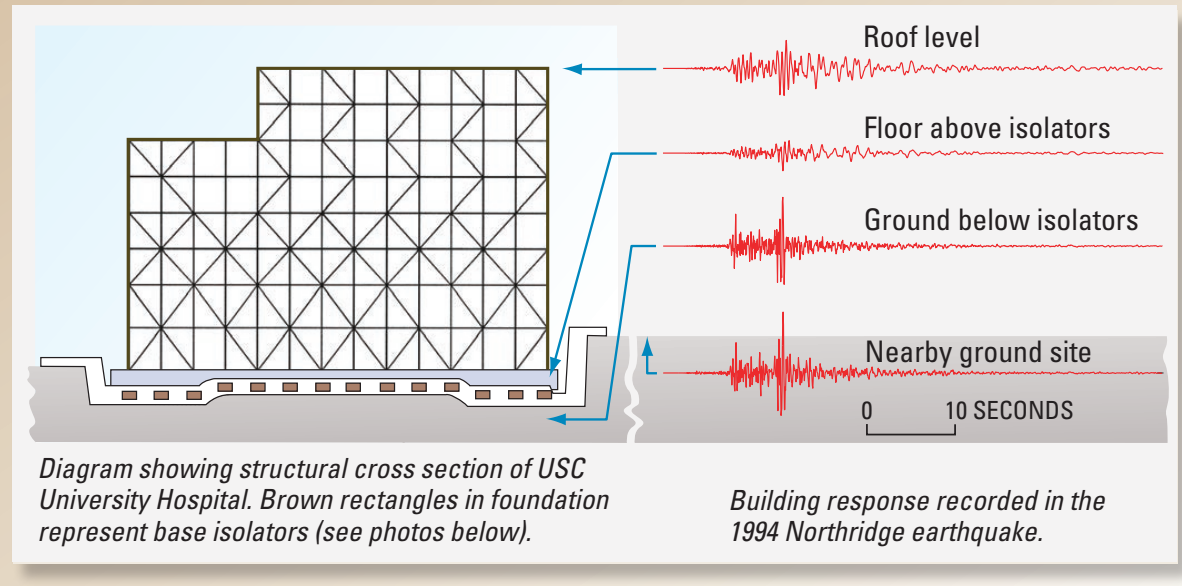

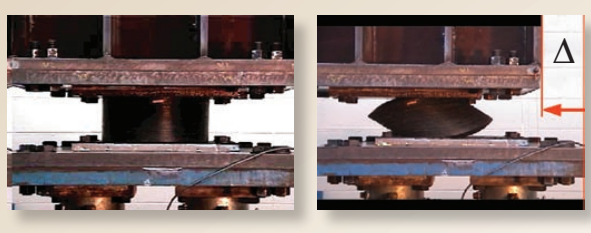

Base isolators in laboratory tests -(left) undeformed isolator, (right) deformed isolator with sizeable horizontal displacement ( $\Delta$ ). Such displacement of isolators prevents large displacements of floors of the building above.

whereas with a conventional foundation the roof-level shaking would have exceeded that measured on the ground.

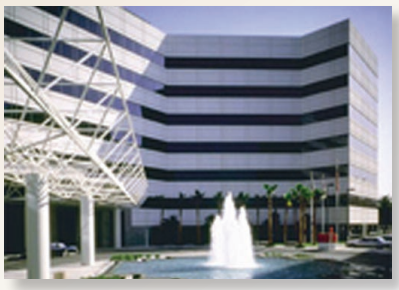

The USC University Hospital was built with base isolators to allow it to withstand strong earthquake shaking. The success of this design strategy was demonstrated in the 1994 Northridge quake, when the hospital and its contents suffered no damage, despite the severe ground shaking produced by the quake.

\section{SHAKING IN AN IRREGULAR STRUCTURE}

\author{
Buildings are complex \\ structures. They are made \\ of multiple elements and \\ components that are \\ stressed and interact \\ with one another when \\ shaken by an earthquake. \\ Buildings vary widely in \\ size, geometry, struc- \\ tural system, construction \\ material, and foundation \\ characteristics. These \\ attributes influence how \\ a building performs when \\ the ground shakes. \\ The 1989 Loma Prieta
} earthquake (magnitude 6.9) set San Francisco's Transamerica Pyramid swaying and rocking. An array of 22 sensors (small arrows) installed by the

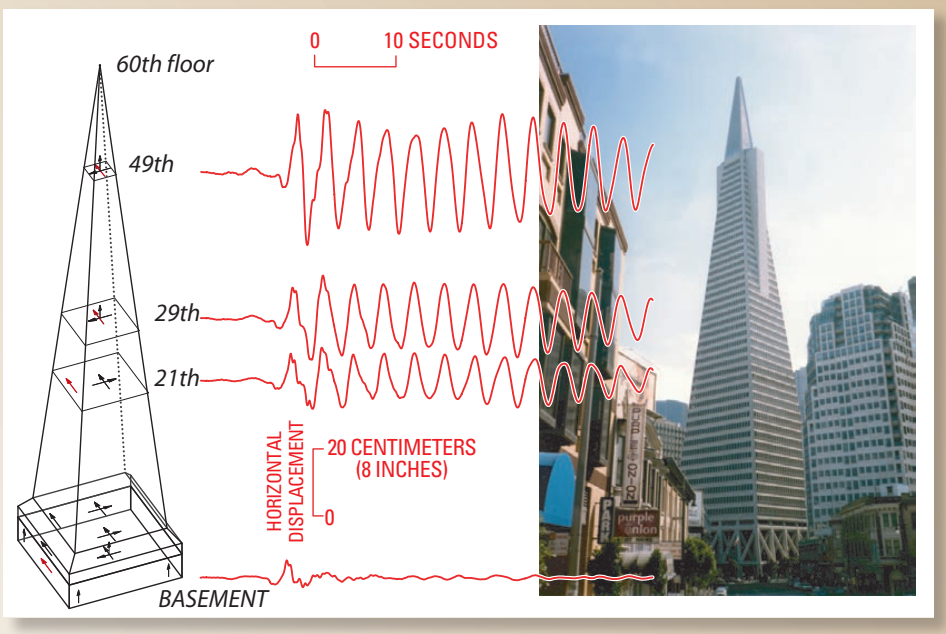

in the basement, as indicated by the recordings (red lines). No significant twisting of the building was measured due to the symmetry of the building about its vertical axis. Located 60 miles from the epicenter of the quake and designed to withstand even larger shocks, the building was undamaged.

Earthquake records from buildings, such as those from the Transamerica Pyramid, allow

U.S. Geological Survey in the steel-frame structure documented that the horizontal displacement on the $49^{\text {th }}$ floor of the building was five times the $1 \frac{1}{2}$ inches measured engineers to verify mathematical models used to predict deformation of a structure from a given pattern of shaking of its foundation. 


\section{ASSESSING THE SAFETY OF BUILDINGS}

New technology allows rapid assessment of a building's state of health after being shaken in an earthquake. The probable degree of damage suffered by the structure can be quickly inferred from motions recorded by an array of sensors distributed at key locations throughout a building. This ability allows a building manager or designated consultant to make a preliminary assessment of whether the safety of the building has been seriously compromised.

A new monitoring system configured by the U.S. Geological Survey, which features instantaneous acquisition of data and automated computation of deformation in a building during an earthquake, has been installed in a 23-story building in San Francisco. With this 30-sensor system, a safety officer in the building or an engineer elsewhere with a communications link will be able to assess the performance and safety of the structure immediately after shaking stops. Such advanced monitoring systems can help to reduce the impact of earthquakes by hastening emergency response actions.

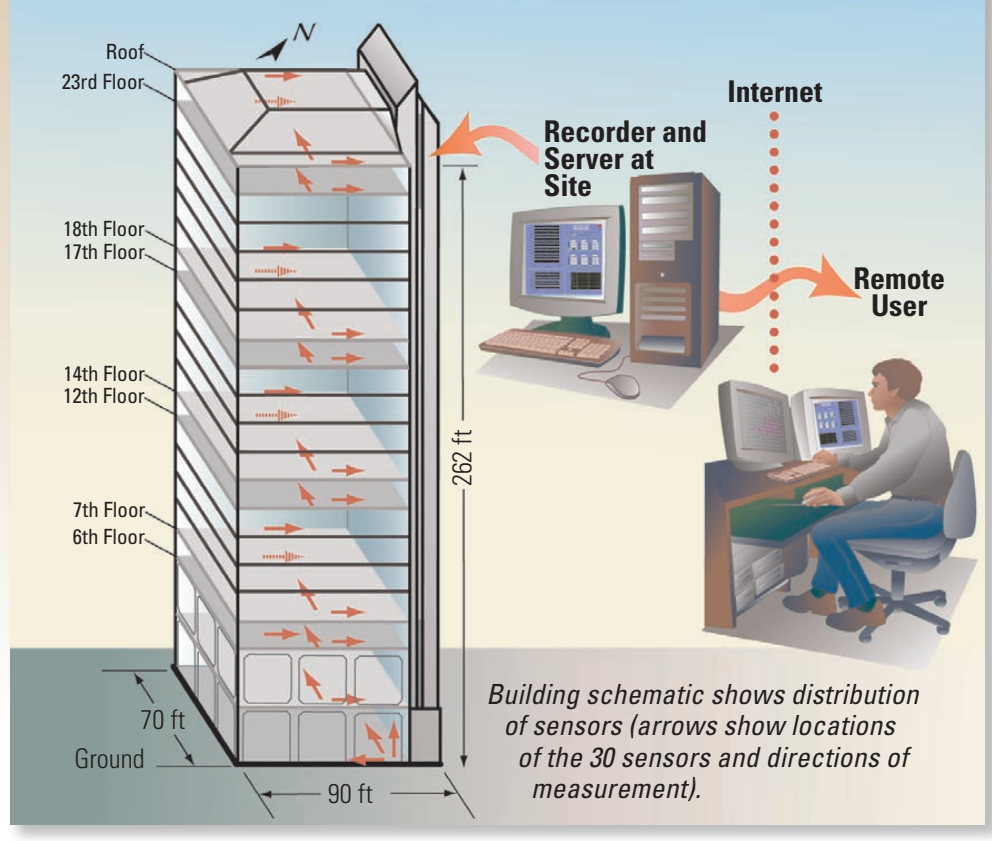

\section{CAPTURING BUILDING PERFORMANCE}

The 1994 Northridge earthquake (magnitude 6.7) in southern California tested the structure that replaced the Olive View Hospital, which was heavily damaged by the 1971 San Fernando shock (see front

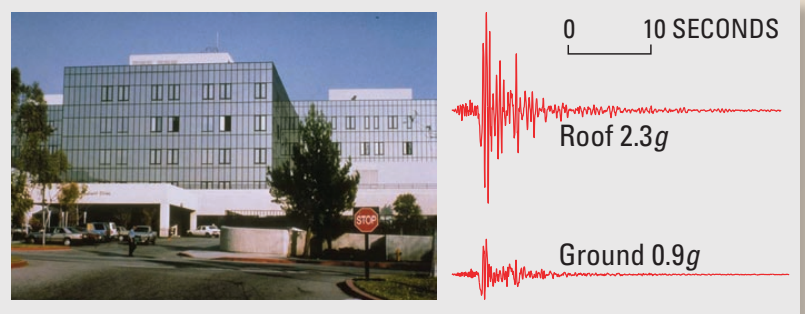
page) and later razed. The replacement building was designed to be stronger than its predecessor and was instrumented by the California Geological Survey.

During the 1994 shock, shaking sensors recorded horizontal acceleration of the ground that was nearly equal to the acceleration of gravity and horizontal acceleration at the roof level that was 2.3 times gravity $(g)$. These motions are among the most severe yet recorded in and adjacent to an engineered structure during a quake. The new building suffered only minor structural damage and remained in operation except for a brief interruption due to a sprinkler-system rupture on the ground floor.

and safety of the structure and initiate an appropriate response.

To improve and modernize seismic monitoring in the United States, particularly in high-risk seismic regions, Congress in 2000 authorized the Advanced National Seismic System (ANSS). The ANSS plan, now being implemented by the USGS and cooperators, envisions 3,000 new sensors placed in urban structures to monitor their response to strong earthquakes, in addition to 3,000 new ground sensors. Placing sensors in many more buildings in active seismic regions will further hasten efforts to better safeguard buildings and their occupants and contents against damage and loss in future earthquakes.
Mehmet Celebi, Robert A. Page, and Erdal Safak Edited by

James W. Hendley II and Peter H. Stauffer

Layout and design by

Susan Mayfield and Sara Boore

\section{COOPERATING ORGANIZATIONS}

California Geological Survey California Department of Transportation California Institute of Technology

California State University, Northridge City of Los Angeles

Consortium of Organizations for Strong-Motion Observation Systems

Federal Deposit Insurance Corporation Federal Highway Administration General Services Administration Jet Propulsion Laboratory, NASA

Metropolitan Water District of Southern California

Missouri Department of Transportation

Oregon Department of Highways

Pacific Gas and Electric Company

U.S. Army Corps of Engineers

U.S. Bureau of Reclamation

U.S. Department of Veteran Affairs University of Alaska

University of California, Los Angeles University of Memphis

University of Puerto Rico, Mayagüez

Washington Department of Highways

Washington Department of Natural Resources

Many city and county agencies and private building owners

For more information contact:

Earthquake Information Hotline (650) 329-4085

U.S. Geological Survey, Mail Stop 977

345 Middlefield Road, Menlo Park, CA 94025 http://earthquake.usgs.gov

This fact sheet and any updates to it are available online at: http://pubs.usgs.gov/fs/2003/fs068-03/ 